\title{
Tannic acid mediated induction of apoptosis in human glioma Hs 683 cells
}

\author{
JIAN ZHANG $^{1 *}$, DONG CHEN ${ }^{2 *}$, DIAN-MING HAN ${ }^{2}$, YAN-HAO CHENG $^{1}$, \\ $\mathrm{CHAO}^{\mathrm{DAI}}{ }^{1}$, XIU-JIE WU ${ }^{1},{\text { FENG-YUAN } \mathrm{CHE}^{3} \text { and XUE-YUAN HENG }}^{1}$ \\ ${ }^{1}$ Department of Neurosurgery, Linyi People's Hospital, Linyi, Shandong 276000; \\ ${ }^{2}$ Department of Clinical College, Binzhou Medical University, Yantai, Shandong 264000; \\ ${ }^{3}$ Department of Neurology, Linyi People's Hospital, Linyi, Shandong 276000, P.R. China
}

Received November 7, 2016; Accepted November 3, 2017

DOI: $10.3892 / \mathrm{ol} .2018 .8197$

\begin{abstract}
Tannic acid (TA), a natural plant compound, is known to induce the death of cancer cells in various types of cancer. The present study was designed with the aim of exploring the effects of tannic acid in vitro on HS 683, a glioma cell line, and to study the mechanism involved in the induction of cytotoxicity and apoptosis by TA. TA exhibited maximum cytotoxic activity against the Hs 683 cell line. Nuclear morphology, 4',6-diamidino-2-phenylindole staining and annexin $\mathrm{V} /$ propidium iodide apoptosis assaying of $\mathrm{Hs}$ 683 cells confirmed that cell death was due to the induction of apoptosis by TA. Further mechanistic study of TA on Hs 683 cells revealed that it decreased cell growth with increasing TA concentration, that resulted in the activation of pro-caspase 3 and caspase 9 and the cleavage of poly (ADP-ribose) polymerase, implying the induction of apoptosis cascades. Biochemical evidence of apoptosis resulted from the loss of mitochondrial membrane potential and increased intracellular reactive oxygen species production by TA in a dose-dependent manner. Based on this data, TA may be further investigated as a potential anticancer therapeutic lead.
\end{abstract}

\section{Introduction}

Gliomas are considered to be one of the most aggressive human cancer types, primarily affecting the central nervous system, and accounting for up to $50 \%$ of all primary malignant tumors of the central nervous system, with high incidence and mortality rates globally (1). Gliomas are classified by the World Health Organization according to the degree of

Correspondence to: Dr Xue-Yuan Heng, Department of Neurosurgery, Linyi People's Hospital, 49 Yizhou Road, Linyi, Shandong 276000, P.R. China

E-mail: hengxueyuan19@hotmail.com

${ }^{*}$ Contributed equally

Key words: tannic acid, glioma cell line Hs 683, apoptosis malignancy, into four separate grades with increasing aggressiveness (2). Patients with grade 4 gliomas have an average survival period of $\leq 14$ months, despite the availability of multimodal therapies, including surgery, radiotherapy and finally chemotherapy $(3,4)$. The slow penetration of gliomas into the brain tissue surrounding the tumor prevents surgery and radiation therapy. Furthermore, glioma progression is primarily supported by the microenvironment that surrounds it. As a result, current treatments become ineffective, as they are unable to inhibit the supportive effect provided by the tumor microenvironment. More notably, the cells that constitute the microenvironment are more genetically stable compared with the cells that make up the tumor. Malignant glioma appears to proliferate indefinitely. Therefore, present research attempts to develop a novel method in order to inhibit the progression of a tumor and additionally inhibit the supportive effect that the tumor microenvironment provides to tumor cells. Currently, phytochemicals are being explored as potential candidates for the treatment of various cancer types and have gained a substantial amount of attention due to positive results $(5,6)$. Polyphenolic phytochemicals are present in abundance in plants and are known to have antitumor, anti-inflammatory, chemosensitization and cryo-protective effects (5-10). Polyphenolic compounds that are plant-derived and have a molecular weight in the range of 500-3,000 Da are known as tannins, and these tannins may be categorized as either condensed or hydrolysable tannins (11). As a hydrolysable tannin, tannic acid (TA) exists in various forms and is present in abundance in food plants. In one animal model, TA was demonstrated to have chemoprotective activity against cancer, including in hairless mice, and was able to suppress $\sim 70 \%$ of the promotion of skin tumor induced by ultraviolet-B radiations (12) In addition to functioning as a potential chemopreventive candidate, previously TA has been revealed to directly inhibit the growth of cancer cells. Various studies are available where TA has been revealed to suppress proliferation in various types of cancer cells in vitro and induce cancer cell death by apoptosis (13-16). However, the pathway by which TA operates inside a cell has not been documented yet and requires further study. One previous study examined proteasome inhibition by TA in cancer cells, which led to growth arrest or apoptosis of cancer cells (17). Previously, a study also 
demonstrated that TA may offer a novel way to treat glioma as it may act within the tumor microenvironment and lead to inhibition of cluster of differentiation 38 (18). Therefore, the present study was designed with the aim of exploring the effects of TA in vitro on HS 683, a glioma cell line, and to study the mechanism involved in the induction of cytotoxicity and apoptosis by TA.

\section{Materials and methods}

Chemicals and reagents. RPMI-1640, streptomycin, penicillin G, 3-(4, 5-dimethylthiazol-2yl)-2,5-diphenyltetrazolium bromide (MTT), dimethyl sulfoxide (DMSO), TA, Rhodamine-123 and 2,7-Dichlorodihydrofluorescein diacetate (DCFH-DA) were obtained from Sigma-Aldrich, Merck KGaA (Darmstadt, Germany). Foetal bovine serum (FBS) was obtained from Gibco (Thermo Fisher Scientific, Inc.,Waltham, MA, USA). Pro caspase 3, caspase 9, poly (ADP-ribose) polymerase (PARP), $\beta$ actin and Annexin V/propidium iodide (PI) was purchased from Santa Cruz Biotechnology, Inc. (Dallas, TX, USA).

Cell culture, growth conditions and treatment. A panel of five cancer cell lines, including colorectal adenocarcinoma cell line LS-180, human breast adenocarcinoma cell line MCF-7, human brain glioma cell line Hs 683, mouse neuroblastoma cell line $\mathrm{N} 2 \mathrm{a}$ and human promyelocytic leukemia cell line HL-60 were acquired from the European Collection of Authenticated Cell Cultures (Public Health England, London England) were used for initial analysis. RPMI-1640 media complemented with $10 \%$ FBS, streptomycin (100 mg/l), penicillin G (70 mg/l), and $\mathrm{NaHCO}_{3}(3.7 \mathrm{~g} / \mathrm{l})$ were used to culture the cells, maintained in a humidified environment in a $\mathrm{CO}_{2}$ incubator at $37^{\circ} \mathrm{C}$ with $5 \% \mathrm{CO}_{2}$ at $98 \%$ humidity. Cells were treated with a range of concentrations of TA dissolved in DMSO, and control cells were treated with vehicle only $(<0.2 \%$ DMSO).

Viability assay. An MTT assay was performed to assess the effect of TA on cell viability. Cells were seeded at a density of $0.20 \times 10^{5}$ cells/well in 96 -well plates for $24 \mathrm{~h}$. After $24 \mathrm{~h}$, cells were treated for $48 \mathrm{~h}$ with different concentrations of TA $(0,1,5$ and $10 \mu \mathrm{M})$. At $4 \mathrm{~h}$ prior to the termination of the experiment, MTT at a concentration of $2.5 \mathrm{mg} / \mathrm{ml}$ was added. Media was removed, and formazan crystals were dissolved by adding $150 \mu \mathrm{l}$ of DMSO and with gentle agitation on an orbital shaker for 3-4 min. Absorbance was measured at $570 \mathrm{~nm}$ using a microplate reader.

Mitochondrial membrane potential (MMP) assay. Fluorescence of Rhodamine-123 was used to monitor changes in MMP. Loss of Rhodamine-123 from the mitochondria decreases the intracellular fluorescence intensity during cell apoptosis due to the depolarization of MMP. In brief, Hs 683 cells were treated with TA for $48 \mathrm{~h}$ at a range of concentrations $(0,1,5$ and $10 \mu \mathrm{M})$. Rhodamin-123 was added $30 \mathrm{~min}$ prior to the termination of the experiment, and incubated at $37^{\circ} \mathrm{C}$ for $30 \mathrm{~min}$. Cells were centrifuged at $400 \mathrm{x} \mathrm{g}$ for $5 \mathrm{~min}$ at $20^{\circ} \mathrm{C}$ and then washed three times with phosphate buffered saline (PBS). Fluorescent intensity was measured at an excitation wavelength of $488 \mathrm{~nm}$ and emission wavelength of
$529 \mathrm{~nm}$ using a fluorescence microplate reader. The fluorescence of each TA-treated concentration group was compared with an untreated group in three independent experiments.

Nuclear morphology by DAPI. Cells were seeded in a 6-well plate at a density of $1 \times 10^{6}$ cells/well for $24 \mathrm{~h}$. After $24 \mathrm{~h}$, cells were treated with TA at different concentrations $(0,1,5$ and $10 \mu \mathrm{M})$ and were incubated for $48 \mathrm{~h}$. Cells were harvested using trypsinization and fixed with acetic acid and methanol (1:3 concentration) for $6 \mathrm{~h}$. Following incubation, cells were centrifuged at $400 \mathrm{x} \mathrm{g}$ for $5 \mathrm{~min}$ at $20^{\circ} \mathrm{C}$, and pellets were resuspended in acetic acid:methanol solution. Cells were then plated on chilled glass slides. DAPI was added for 20-30 min in the dark at a concentration of $1 \mu \mathrm{g} / \mathrm{ml}$ at $25^{\circ} \mathrm{C}$ and images were taken using a fluorescence microscope at x40 magnification.

Assay for reactive oxygen species (ROS). Measurement of ROS in Hs 683 cells was measured using DCFH-DA. Cells were treated with TA at a range of concentrations $(0,1,5$ and $10 \mu \mathrm{M})$ for $48 \mathrm{~h}$. All cells were collected using trypsinization, washed three times with PBS, and then resuspended in $500 \mu \mathrm{l}$ of PBS containing DCFH-DA at a concentration of $10 \mu \mathrm{M}$ for $30 \mathrm{~min}$ in the dark at $37^{\circ} \mathrm{C}$. Then, all samples were analysed immediately using a flow cytometer with CellQuest software version 5.1 BD Biosciences (BD FACSCalibur ${ }^{\mathrm{TM}}$; BD Biosciences, Franklin Lakes, NJ, USA). A total of 20,000 events for analysis were captured.

Detection of apoptosis via Annexin V/PI. Hs 683 cells were seeded at a density of $1 \times 10^{6}$ cells/well in 6 -well plates and were treated with TA at a range of concentrations $(0,1,5$ and $10 \mu \mathrm{M})$ for $48 \mathrm{~h}$. Treated samples were collected and washed twice with PBS and cells were resuspended in $500 \mu \mathrm{l}$ of binding buffer with Annexin in the dark for 20 min according to the manufacturer's protocol. Apoptotic population was analysed using a flow cytometer with CellQuest software version 5.1 BD Biosciences (BD FACSCalibur; BD Biosciences).

Western blot analysis. Hs 683 cells were seeded in a 6-well plate for $24 \mathrm{~h}$ at a density of $1 \times 10^{6}$ cells/well. After $24 \mathrm{~h}$, cells were treated with TA at a range of different concentrations $(0,1,5$ and $10 \mu \mathrm{M})$ for $48 \mathrm{~h}$. Following treatment, cells were lysed using a RIPA buffer (Sigma-Aldrich, Merck KGaA, Darmstadt, Germany) and protein content was quantified using Bradford reagent. Proteins $(60 \mu \mathrm{g})$ were loaded in SDS-PAGE PARP (8\% SDS-PAGE), Caspase 3 (15\% SDS-PAGE), Caspase 9 (15\% SDS-PAGE), $\beta$-actin (10\% SDS-PAGE) and were electro-transferred onto a PVDF membrane (Bio-Rad Laboratories, Inc., Hercules, CA, USA) for $2 \mathrm{~h}$ at $100 \mathrm{~V}$. Non-specific binding of protein membranes was blocked using the blocking buffer (TBST; $150 \mathrm{mM} \mathrm{NaCL}, 10 \mathrm{mM}$ Tris-HCL and $0.1 \%$ Tween 20 ) with $5 \%$ skimmed milk at room temperature for $1 \mathrm{~h}$. Primary antibodies PARP (cat no. 9532; dilution 1:1,000); Caspase 3 (cat no. 9662; dilution 1:1,000); Caspase 9 (cat no. 9508; dilution 1:1,000) $\beta$-Actin (cat no. 4970; dilution 1:1,500) were obtained from Cell Signaling Technology Inc., (Danvers, MA, USA) were incubated with different protein membranes for $6 \mathrm{~h}$ at $20^{\circ} \mathrm{C}$ and washed twice with blocking buffer (TBST) for $5 \mathrm{~min}$ each. Then, horseradish peroxidase conjugated anti-rabbit secondary antibody (cat. no. 93702; 
A

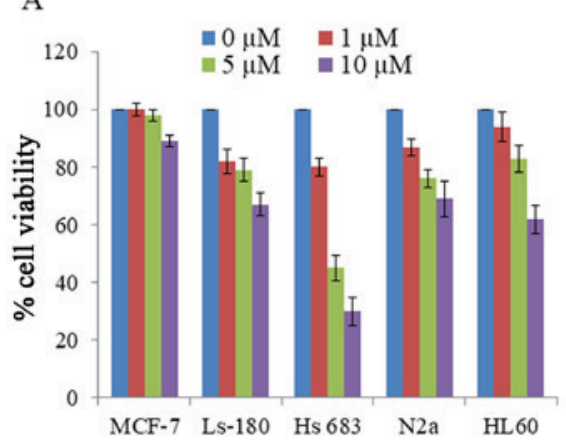

B

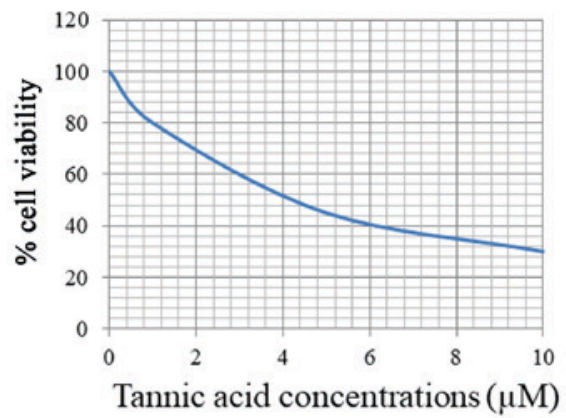

Figure 1. TA inhibits cell viability. (A) TA inhibited the viability of cell lines MCF-7, Ls-180, Hs 683, N2a and HL60 in a concentration-dependent manner, most notably reducing the cell viability of the human brain glioma cell line Hs 683. (B) IC50 of Hs 683 cells was determined to be $4.2 \mu \mathrm{M}$. TA, tannic acid.

dilution 1:2,000) were obtained from Cell Signaling Technology Inc. were used for incubation for $1 \mathrm{~h}$ at $20^{\circ} \mathrm{C}$ and washed again three times with blocking buffer (TBST). The bands of proteins were visualised using an enhanced chemiluminescence kit (GE Healthcare, Chicago, IL, USA) on an X-ray film.

Statistical analysis. All data is presented as the mean (of three independent experiments) \pm the standard deviation. GraphPad Instat v3 software (GraphPad software Inc., La Jolla, CA, USA) was used for statistical analysis. A one-way analysis of variance was used for statistical analysis with Bonferroni's correction applied. $\mathrm{P}<0.05$ was considered to indicate a statistically significant difference.

\section{Results}

TA inhibits the cell viability of $H s$ 683. Initial cytotoxicity of TA was assessed using an MTT assay on various cancer cell lines. Cells were treated with different concentrations of TA for $48 \mathrm{~h}$, and revealed different levels of viability inhibition by TA as presented in Fig. 1A. Human brain glioma cell line Hs 683 was the most sensitive to the effect of TA, particularly at the $10 \mu \mathrm{M}$ concentration, and was selected as the target cell line for further studies. Viability of Hs 683 cells was reduced by TA in a concentration-dependent manner for $48 \mathrm{~h}$ with an $\mathrm{IC}_{50}$ of $4.2 \mu \mathrm{M}$ (Fig. 1B). These results demonstrate that TA had a substantial cytotoxic effect on Hs 683 cells.

TA induces apoptosis in Hs 683 cells. To explore whether TA induces apoptosis in Hs683 cells, cells were treated with differing concentrations of TA $(0,1,5$ and $10 \mu \mathrm{M})$ and the induction of apoptosis was observed using DAPI staining. Under a fluorescence microscope it was observed that apoptotic bodies increased in a concentration-dependent manner compared with the untreated cells that have uniformly bright nuclei (Fig. 2). These results suggest that TA induced apoptotic cell death in a concentration-dependent manner.

ROS assay in Hs683 cells. In the present study, the effect of TA on ROS generation by which the induction of apoptosis takes place in Hs683 cells, was examined by using $\mathrm{DCFH}_{2} \mathrm{DA}$ dye. Results indicated that TA increases the intracellular ROS

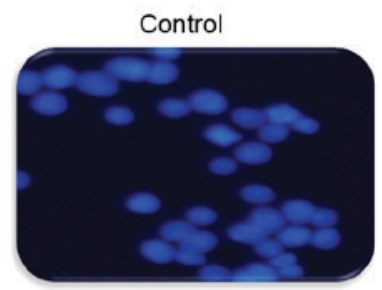

$5 \mu \mathrm{M}$

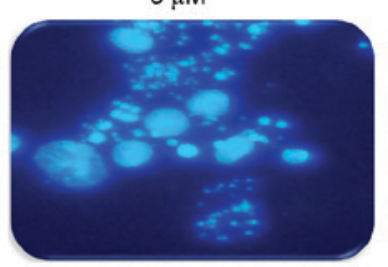

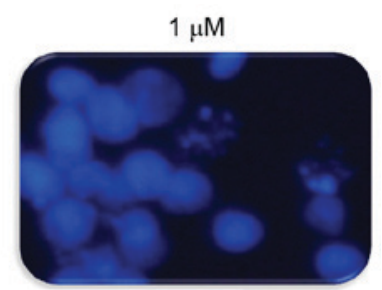

$10 \mu \mathrm{M}$

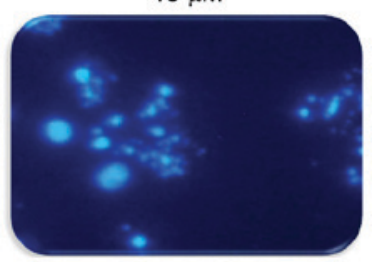

Figure 2. TA induces apoptosis in $\mathrm{Hs} 683$ cells. Cells were treated with a range of concentrations of TA $(0,1,5$ and $10 \mu \mathrm{M})$ and observed using 4'6-diamidino-2-phenylindol staining and a fluorescence microscope at x40 magnification. Apoptotic bodies increased in a concentration-dependent manner. TA, tannic acid.

by $2.86,15.59,40.20$ and $47.35 \%$ at TA concentrations of 0,1 , 5 and $10 \mu \mathrm{M}$ respectively, compared with the untreated control (Fig. 3). Thus, these results indicate that TA generated ROS in a concentration-dependent manner which leads Hs 683 cells towards apoptosis.

MMP loss by TA treatment in glioma Hs683 cells. Mitochondria serve an important function in the progression of apoptosis; loss of MMP is part of the early phase of apoptosis. To investigate whether TA affects MMP, analysis was performed using Rhodamine-123 dye, which reveals the loss of MMP. The results demonstrated that MMP was significantly lost in cells treated with TA at concentrations of $1 \mu \mathrm{M}$ $(\mathrm{P}<0.05), 5 \mu \mathrm{M}(\mathrm{P}<0.01)$ and $10 \mu \mathrm{M}(\mathrm{P}<0.01)$, compared with untreated cells, in a concentration-dependent manner (Fig. 4). Untreated Hs 683 cells retained 96\% fluorescence. Thus, these results suggest that TA induced apoptosis by MMP loss.

Annexin V/PI assay. In order to confirm that TA induces apoptosis, an Annexin V/PI assay was performed. Annexin V/PI staining revealed that the apoptotic population increased to $14.83,30.10$ and $46.94 \%$ at TA concentrations of 1,5 and $10 \mu \mathrm{M}$, 


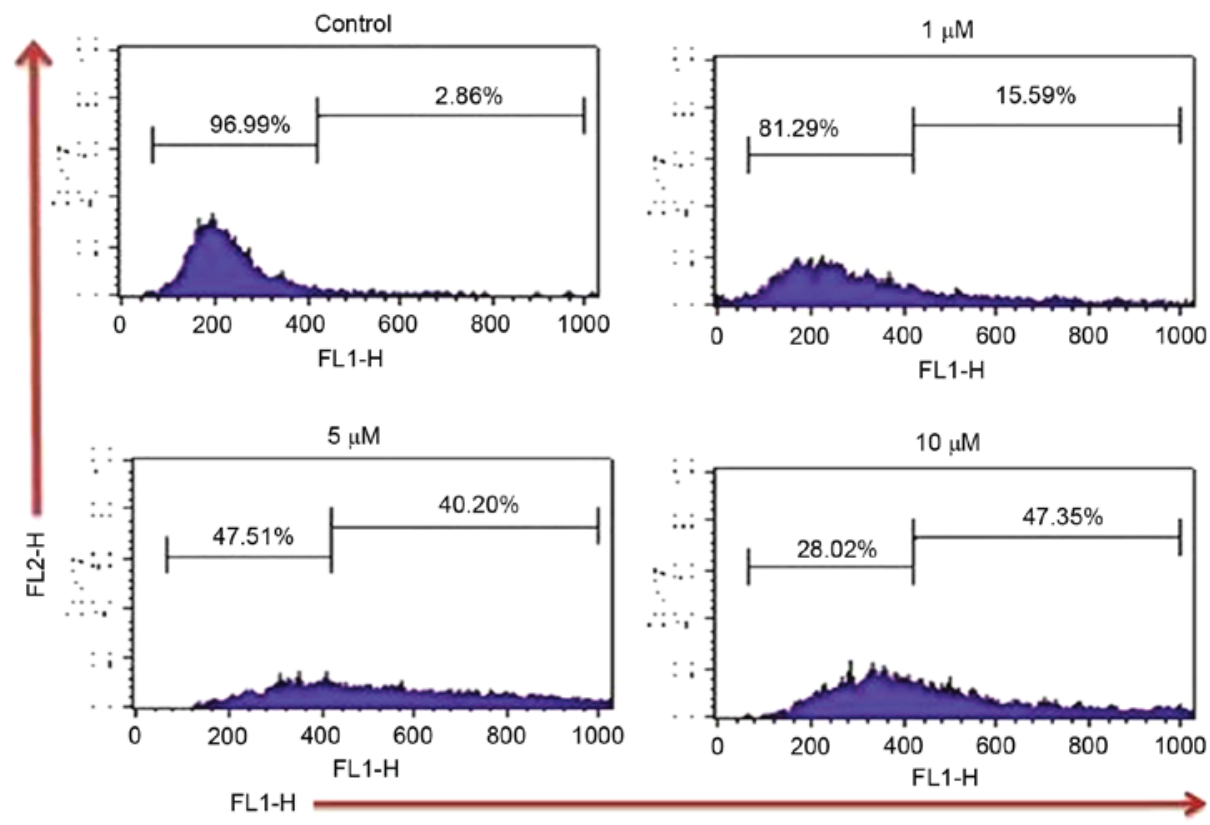

Figure 3. TA generates ROS in a concentration-dependent manner in Hs 683 cells. Generation of ROS in Hs 683 cells treated with a range of concentrations of TA $(0,1,5$ and $10 \mu \mathrm{M})$ was examined using $2^{\prime}, 7^{\prime}$-Dichlorofluorescin diacetate dye. ROS generation increased with an increase in TA concentration. TA, tannic acid; ROS, reactive oxygen species.

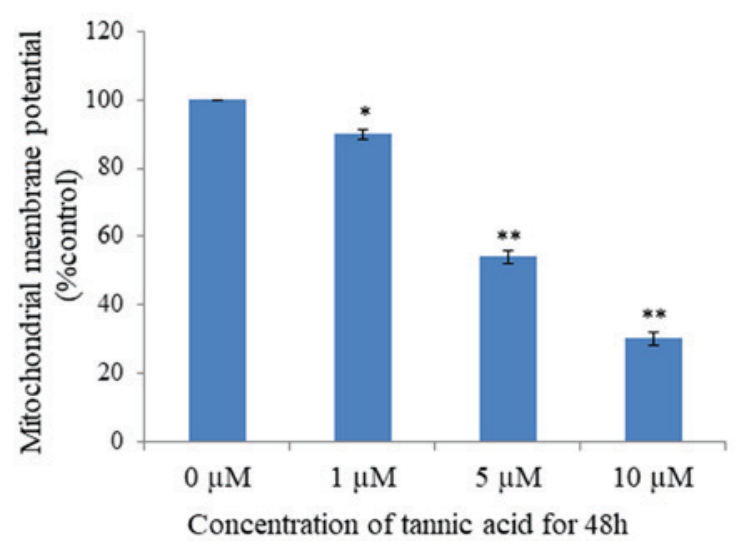

Figure 4. TA treatment results in MMP loss. MMP of Hs 683 cells treated with a range of concentrations of $\mathrm{TA}(0,1,5$ and $10 \mu \mathrm{M})$ was analysed using Rodamin-123 dye. It was revealed that MMP was significantly lost with TA treatment in a concentration-dependent manner, compared with untreated cells. ${ }^{*} \mathrm{P}<0.05$ and ${ }^{* *} \mathrm{P}<0.01$ vs. untreated cells. TA, tannic acid; MMP, mitochondrial membrane potential.

respectively, compared with the untreated control $(0.55 \%)$ (Fig. 5) These results indicate that TA induced apoptosis in a concentration-dependent manner.

TA induces PARP cleavage and caspase activation in Hs 683 cells. Regulation of caspases serves an important function in executing apoptotic cell death (19). Executioner caspases like caspase 3 are activated by initiator caspases, including caspase 8, caspase 9 and caspase 10, and cleave PARP once activated (20). In order to investigate the effect of TA on the activation of caspases, Hs 683 cells were treated with TA for $48 \mathrm{~h}$ and examined using western blot analysis. The results revealed that, at different concentrations, pro-caspase 3 and caspase 9 activation was markedly inhibited with increasing concentrations of TA; however, the expression of cleaved PARP increased in a concentration-dependent manner compared with the untreated sample (Fig. 6). Thus, these results indicate that TA induces apoptosis in a concentration-dependent manner.

\section{Discussion}

In traditional medicine, TA usage has a long history. Previously, TA was administered in conjugation with either activated charcoal or magnesium in order to treat toxic substances, including ptomaine poisoning (21). Neanderthals used to treat burns with the extracts of plants rich in TA unknowingly (22). Chinese traditional medicine also uses TA in a similar manner and it has been part of this practice for a long time (23). The therapeutic efficacy of herbal medicine is also known to be enhanced by TA (24). An increasing number of reports have surfaced over the past few years, examining the chemo-therapeutic potential of TA against various cancer types, and TA has garnered a lot of attention (25-27). In the present study, during the cytotoxic screening of TA against various cancer cell lines, TA demonstrated a strong cytotoxic effect against glioma Hs 683 cells with an $\mathrm{IC}_{50}$ of $4.2 \mu \mathrm{M}$. However, the exact mechanism by which TA affects cancer cells is still not fully understood. A previous study by Nam et al (17), revealed that TA potentially inhibits the activity of specific proteasomes resulting in a build-up of proteasome substrates, specifically cyclin-dependent kinase inhibitor 1B and BCL2 associated X apoptosis regulator. A build-up of these substrates results in the arrest of the cell growth cycle in the G1 phase followed by the induction of apoptosis. The present study revealed that, following the introduction of TA to glioma Hs 683 cells, there was membrane blabbing, chromosome condensation and fragmentation of glioma Hs 683 cells as confirmed by DAPI staining, which are all apoptotic hallmarks. Apoptosis caused 

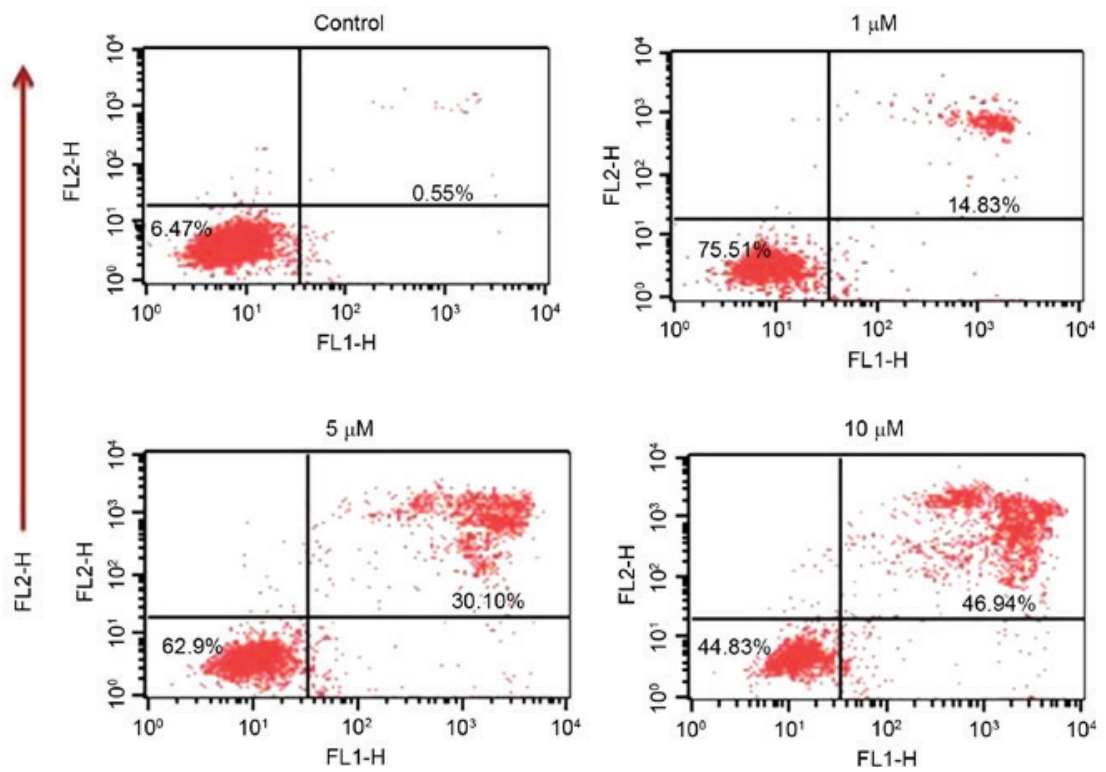

FL1-H

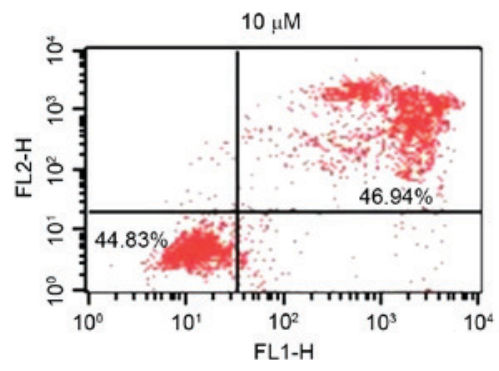

Figure 5. TA induced apoptosis. Cells were treated with a range of concentrations of TA $(0,1,5$ and $10 \mu \mathrm{M})$ and examined using an Annexin V/propidium iodide assay. Results revealed that the apoptotic population increased in a concentration-dependent manner. TA, tannic acid.

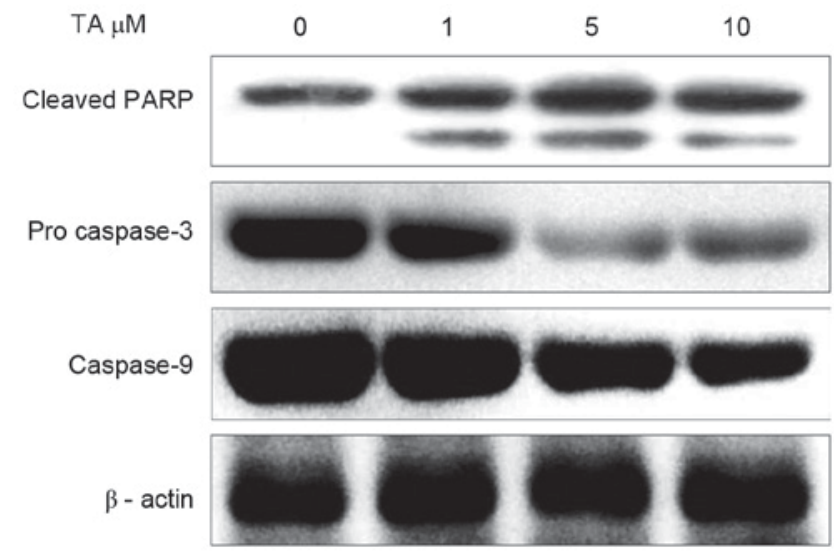

Figure 6. TA induces PARP cleavage and caspase activation in Hs 683 cells. Cells were treated with a range of TA concentrations $(0,1,5$ and $10 \mu \mathrm{M})$ and the activity of cleaved PARP, pro caspase 3 and caspase 9 were examined using western blot analysis. It was revealed that cleaved PARP activity increased with increasing TA concentration, however pro caspase 3 and caspase 9 activity was reduced with increasing TA concentration, compared with the untreated sample. TA, tannic acid; PARP, poly (ADP-ribose) polymerase.

by TA was further confirmed by Annexin V/PI staining. It was revealed that with an increase in the concentration of TA, there was a significant increase in the production of ROS, which was accompanied by a significant increase in the loss of MMP in Hs 683 cells. Therefore, it was concluded that TA induces apoptosis in Hs 683 cells by increasing ROS production, which are known to be responsible for inducing apoptosis in cancer cells by generating transitional pore opening in mitochondria. Induction of apoptosis by TA in Hs 683 cells was further validated by western blot analysis in which the activation of pro-caspase 3, caspase 9 and cleaved parp were observed. From the results obtained it was concluded that TA induced
ROS generation and loss of MMP in glioma Hs 683 cells, which may finally drive the cells towards apoptosis. Therefore, the function of TA as an anticancer agent needs to be evaluated further. These results validate the requirement for further studies to explore the function of polyphenols, particularly TA, in various models of cancer. These studies will assist in the development of a novel treatment for cancer and lead to cancer cell growth inhibition.

\section{Acknowledgements}

Not applicable.

\section{Funding}

This study was supported by Natural Science Foundation of Shandong Province, China (grant no. ZR2014HM077).

\section{Availability of data and materials}

All data generated or analyzed during this study are included in this published article.

\section{Authors' contributions}

JZ and DC designed and planned the study, interpreted the results and wrote the manuscript. $\mathrm{DH}, \mathrm{YC}$ and $\mathrm{CD}$ performed experiments and generated results. XW and FC contributed the reagents and assisted in designing the study. XH drafted the manuscript and interpreted the data. All authors have read and approved the final version of the manuscript.

\section{Ethics approval and consent to participate}

Not applicable. 


\section{Consent for publication}

Not applicable.

\section{Competing interests}

The authors declare that they have no competing interests.

\section{References}

1. Jemal A, Bray F, Center MM, Ferlay J, Ward E and Forman D: Global cancer statistics. CA Cancer J Clin 61: 69-90, 2011.

2. Louis DN, Ohgaki H, Wiestler OD, Cavenee WK, Burger PC, Jouvet A, Scheithauer BW and Kleihues P: The 2007 WHO classification of tumors of the central nervous system. Acta Neuropathol 114: 97-109, 2007.

3. Fuller GN: The WHO classification of tumours of the central nervous system. 4th edition. Arch Pathol Lab Med 132: 906, 2008

4. Rock K, McArdle O, Forde P, Dunne M, Fitzpatrick D, O'Neill B and Faul C: A clinical review of treatment outcomes in glioblastoma multiforme-the validation in a non-trial population of the results of a randomised Phase III clinical trial: Has a more radica approach improved survival? Br J Radiol 85: e729-e733, 2012.

5. Singh S, Sharma B, Kanwar SS and Kumar A: Lead phytochemicals for anticancer drug development. Front Plant Sci 7: 1667, 2016.

6. Rahman MA, Amin AR and Shin DM: Chemopreventive potential of natural compounds in head and neck cancer. Nutr Cancer 62: 973-987, 2010.

7. D'Alessandro N, Poma P and Montalto G: Multifactorial nature of hepatocellular carcinoma drug resistance: Could plant polyphenols be helpful? World J Gastroenterol 13: 2037-2043, 2007.

8. Rudolf E, Andelová H and Cervinka M: Polyphenolic compounds in chemoprevention of colon cancer-targets and signaling pathways. Anticancer Agents Med Chem 7: 559-575, 2007.

9. Stevenson DE and Hurst RD: Polyphenolic phytochemicals-just antioxidants or much more? Cell Mol Life Sci 64: 2900-2916, 2007.

10. Fresco P, Borges F, Diniz C and Marques MP: New insights on the anticancer properties of dietary polyphenols. Med Res Rev 26: 747-766, 2006.

11. Romani A, Ieri F, Turchetti B, Mulinacci N, Vincieri FF and Buzzini P: Analysis of condensed and hydrolysable tannins from commercial plant extracts. J Pharm Biomed Anal 41: 415-420, 2006.

12. Gali-Muhtasib HU, Yamout SZ and Sidani MM: Tannins protect against skin tumor promotion induced by ultraviolet-B radiation in hairless mice. Nutr Cancer 37: 73-77, 2000.

13. Sakagami H, Jiang Y, Kusama K, Atsumi T, Ueha $T$, Toguchi M, Iwakura I, Satoh K, Ito H, Hatano T and Yoshida T: Cytotoxic activity of hydrolyzable tannins against human oral tumor cell lines-a possible mechanism. Phytomedicine 7: 39-47, 2000 .
14. Pan MH, Lin JH, Lin-Shiau SY and Lin JK: Induction of apoptosis by penta-O-galloyl-beta-D-glucose through activation of caspase-3 in human leukemia HL-60 cells. Eur J Pharmacol 381: 171-183, 1999.

15. Wang CC, Chen LG and Yang LL: Cuphiin D1, the macrocyclic hydrolyzable tannin induced apoptosis in HL-60 cell line. Cancer Lett 149: 77-83, 2000.

16. Yang LL, Lee CY and Yen KY: Induction of apoptosis by hydrolyzable tannins from Eugenia jambos L. on human leukemia cells. Cancer Lett 157: 65-75, 2000.

17. Nam S, Smith DM and Dou QP: Tannic acid potently inhibits tumor cell proteasome activity, increases p27 and Bax expression, and induces G1 arrest and apoptosis. Cancer Epidemiol Biomarkers Prev 10: 1083-8, 2001.

18. Blacher E, Levy A, Baruch BB, Green KD, Garneau-Tsodikova S, Fridman M and Stein R: Targeting CD38 in the tumor microenvironment: A novel approach to treat glioma. Cancer Cell Microenvironment 2: 2, 2015.

19. Lavrik IN, Golks A and Krammer PH: Caspases: Pharmacological manipulation of cell death. J Clin Invest 115: 2665-2672, 2005.

20. Sakahira H, Enari M and Nagata S: Cleavage of CAD inhibitor in CAD activation and DNA degradation during apoptosis. Nature 391: 96-99, 1998.

21. Daly JS and Cooney DO: Interference by tannic acid with the effectiveness of activated charcoal in 'Universal Antidote'. Clin Toxicol 12: 515-522, 1978

22. Hupkens P, Boxma H and Dokter J: Tannic acid as a topical agent in burns: Historical considerations and implications for new developments. Burns 21: 57-61, 1995.

23. Shi-Tsi S: Use of combined traditional Chinese and Western medicine in the management of burns. Panminerva Med 25: 197-202, 1983.

24. Mala A and Tulika T: Therapeutic efficacy of Centella asiatica (L.) and Momordica charantia: As traditional medicinal plant. J Plant Sci 3: 1-9, 2015.

25. Naus PJ, Henson R, Bleeker G, Wehbe H, Meng F and Patel T: Tannic acid synergizes the cytotoxicity of chemotherapeutic drugs in human cholangiocarcinoma by modulating drug efflux pathways. J Hepatol 46: 222-229, 2007.

26. Ramanathan R, Tan $\mathrm{CH}$ and Das NP: Cytotoxic effect of plant polyphenols and fat-soluble vitamins on malignant human cultured cells. Cancer Lett 62: 217-224, 1992.

27. Booth BW, Inskeep BD, Shah H, Park JP, Hay EJ and Burg KJ: Tannic acid preferentially targets estrogen receptor-positive breast cancer. Int J Breast Cancer 2013: 369609, 2013.

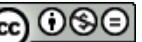

$$
\begin{aligned}
& \text { This work is licensed under a Creative Commons } \\
& \text { Attribution-NonCommercial-NoDerivatives } 4.0 \\
& \text { International (CC BY-NC-ND 4.0) License. }
\end{aligned}
$$

